\title{
Service Life Prediction and Lateral Bearing Capacity Analysis of Piles Considering Coupled Corrosion-Temperature Deterioration Processes
}

\author{
Yue Li ${ }^{1}$, Youliang Chen ${ }^{1, *}$, Wei Shao ${ }^{2}$, Juhui Zhang ${ }^{1}$, Shaoming Liao ${ }^{3}$ and Tomas Manuel Fernandez-Steeger ${ }^{4}$ \\ 1 Department of Civil Engineering, University of Shanghai for Science and Technology, \\ Shanghai 200093, China; $181520110 @ s t . u s s t . e d u . c n$ (Y.L.); zhjhui@usst.edu.cn (J.Z.) \\ 2 College of Ocean Science and Engineering, Shanghai Maritime University, Shanghai 201306, China; \\ weishao@shmtu.edu.cn \\ 3 Department of Geotechnical Engineering, Tongji University, Shanghai 200092, China; engcent@tongji.edu.cn \\ 4 Department of Engineering Geology, Technische Universität Berlin, 10587 Berlin, Germany; \\ fernandez-steeger@tu-berlin.de \\ * Correspondence: ylchen@usst.edu.cn
}

check for

updates

Citation: Li, Y.; Chen, Y.; Shao, W.; Zhang, J.; Liao, S.; Fernandez-Steeger, T.M. Service Life Prediction and Lateral Bearing Capacity Analysis of Piles Considering Coupled Corrosion-Temperature Deterioration Processes. J. Mar. Sci. Eng. 2021, 9, 614. https://doi.org/10.3390/ jmse9060614

Academic Editor: Marcello Di Risio

Received: 26 April 2021

Accepted: 31 May 2021

Published: 3 June 2021

Publisher's Note: MDPI stays neutral with regard to jurisdictional claims in published maps and institutional affiliations.

Copyright: (c) 2021 by the authors. Licensee MDPI, Basel, Switzerland. This article is an open access article distributed under the terms and conditions of the Creative Commons Attribution (CC BY) license (https:/ / creativecommons.org/licenses/by/ $4.0 /)$.

\begin{abstract}
High temperatures can enhance the chloride diffusion coefficient and this poses a threat to reinforced concrete $(\mathrm{RC})$ piles. This study intends to propose predictive models that can evaluate the service life and lateral bearing behaviour of reinforced concrete piles subjected to marine environments and varying temperatures. The models show that temperature can accelerate the diffusion rate of chloride and increase the concentration of free chloride in concrete. The distribution law of chloride concentration is obtained by considering the ageing effect as well. Deterministic and probabilistic models are proposed to assess the time to corrosion initiation and propagation. The stiffness degradation coefficient is introduced in the analysis of the lateral bearing capacity of $\mathrm{RC}$ piles. The results show that high temperature can decrease the service life of piles and the life spans obtained from deterministic and probabilistic methods are similar; however, the predictions of the latter are more conservative. Temperature can enhance the current density and boost corrosion products, which leads to pile cracking. The rust appearing on the steel surface would make the stiffness degradation coefficient drop sharply. The lateral bearing capacity analysis is conducted from the perspectives of shear force, displacement and bearing moment of the piles.
\end{abstract}

Keywords: reinforced concrete piles; corrosion; temperature; service life prediction; lateral bearing capacity

\section{Introduction}

Laterally loaded piles play a vital role in structures exposed in marine environments, such as bridges, docks, harbours and offshore platforms. Their serviceability and durability suffer from great deterioration that is induced by chloride ingress [1,2]. The application of deicing salts causes substantial long-term deterioration and a reduction in structural safety, especially for poor durability design specifications [3]. Chloride ions cannot directly participate in corrosion reactions but instead act as "catalytic porters" that destroy the passivation layer of reinforcements and increase the volume of corrosion products [4,5]. With the development of the corrosion process, rust can cause concrete tensile stress that may be sufficiently large to induce internal microcracking. The associated spalling of concrete cover is a common problem in concrete structures. An increase in temperature will speed up the rate of chemical reactions, especially for structural members exposed to high-temperature conditions. High temperatures can decrease the physical binding of chloride ions and free them due to higher thermal vibration [6]. Therefore, the changes in exposure temperature have a substantial effect on chloride diffusion into the pile for a 
certain relative humidity. Corrosion damage of reinforcements in $\mathrm{RC}$ structures caused by chloride-ingress attacks are the main problem for the durability of concrete elements [7].

Previous studies have been conducted to seek the mechanisms of chloride-induced corrosion in RC structures and the performance of pile foundations influenced by the deterioration of structures. Isteita and $\mathrm{Xi}$ [8] conducted a systematic experimental study using a new testing method and concrete specimens were subjected to different temperature gradients and chloride concentrations on the boundary. The test data showed that the temperature variation can significantly increase the chloride penetration process when the temperature and chloride concentration gradients are in the same direction. Hussain et al. [9] indicated that an increase in temperature from $20^{\circ} \mathrm{C}$ to $70{ }^{\circ} \mathrm{C}$ caused a 5 -fold reduction in the chloride threshold and reduced the pore solution $\mathrm{pH}$. High temperatures are expected to reduce corrosion resistance by increasing the rates of chloride ingress and corrosion reactions. Liu and Weyers [10] cast a total of 44 simulated bridge deck slabs and corrosion parameters were measured over a 5-year period. They developed a nonlinear regression model which demonstrated that corrosion of steel is a function of the concrete chloride content, temperature, ohmic resistance and active corrosion time. Daniel et al. [11] performed a condition assessment of the wharf built for shipbuilding circa 1960 at the Fore River Shipyard. They found that the vertical piles supporting the wharf were severely deteriorated and that the wharf could even collapse in a severe storm, such as a hurricane. Cui et al. [12] argued that the deterioration of soil-cement and pile defects aggravated the deterioration effects on the bearing capacity of mixed piles and the settlement of composite foundations with an increase in age. Numerous studies have been conducted to investigate concrete corrosion from the perspectives of chloride and temperature. However, few studies have sought the relation between the lateral bearing capacity of piles and the coupled effect of corrosion-temperature.

In this paper, predictive models are given to estimate the service life of piles in marine environments by taking into consideration chloride ingress and temperature variations. Long-term predictions of service life are inherently uncertain since it is very difficult to ensure that no deterioration processes occurred in the whole phase. Thus, the assessment models include deterministic and probabilistic assessments for comparison. The distributions of the chloride concentration and service life of piles are obtained with predictive models. Moreover, the diffusion rate, current density and corrosive depth of the reinforcements can be calculated via models. The stiffness degradation coefficient is introduced here to act as a liaison between chloride corrosion and bearing capacity of piles. High temperature can increase the current density which leads to a dramatic decrease in the degradation coefficient. The analysis of the lateral bearing capacity is developed from the shear force, displacement and bending moment of piles.

\section{Basic Model for Service Life Prediction}

The corrosion time can be divided into two phases: corrosion initiation and corrosion propagation [13-16]. As shown schematically in Figure 1, the service life $\left(t_{s}\right)$ can be defined as the sum of the time to initiation $\left(t_{1}\right)$ and the time to propagation $\left(t_{2}\right)$. In the first phase, chloride ions from the external environment migrate into the concrete cementitious matrix until the chloride content $(C)$ reaches a threshold value $\left(C_{t h}\right)$. The passive film at the steel surface is then damaged and rust starts to form. The volume of the corrosion products can be approximately 2-8 times that of the original volume of the steel, which can generate sufficiently large tensile stress, leading to concrete cracking and the failure of RC piles.

Based on previous studies, Fick's second law is a classical and widely used approach for evaluating the chloride ion concentration in structures [2,3,15,17-22], as given in Equation (1). Considering the initial and boundary conditions (Equation (2)) introduced by Collepardi $[23,24]$, Equation (1) can be transformed into Equation (3), which provides an 
analytical solution to describe the diffusion process. The equation considers the mechanical and physical aspects [25]:

$$
\begin{gathered}
\frac{\partial C}{\partial t}=D\left(\frac{\partial^{2} C}{\partial x^{2}}+\frac{\partial^{2} C}{\partial y^{2}}\right) ; \\
C(x, 0)=C_{0} ; C(0, t)=C_{s} ; C(\infty, t)=C_{0} ; \\
C(x, t)=C_{0}+\left(C_{s}-C_{0}\right)\left[1-\operatorname{erf}\left(\frac{x}{2 \sqrt{D t}}\right)\left(\frac{y}{2 \sqrt{D t}}\right)\right] ; \\
\operatorname{erf}(x)=\frac{2}{\sqrt{\pi}} \int_{0}^{x} e^{-t^{2}} d t,
\end{gathered}
$$

where $C$ is the chloride concentration $\left(\mathrm{kg} / \mathrm{m}^{3}\right), t$ is the exposure period in the chloride environment (s), $x$ is the distance from the surface $(\mathrm{mm}), D$ is the chloride diffusion coefficient $\left(\mathrm{m}^{2} / \mathrm{s}\right), C_{0}$ is the initial chloride concentration existing in concrete $\left(\mathrm{kg} / \mathrm{m}^{3}\right)$, $C_{S}$ is the chloride concentration on the surface of the structure $\left(\mathrm{kg} / \mathrm{m}^{3}\right)$ and $\operatorname{erf}\left({ }^{*}\right)$ is the Gaussian error function that is presented by Equation (4) which describes the evolution of the chloride diffusion front in the direction $x$ at a time $t[18,25]$.

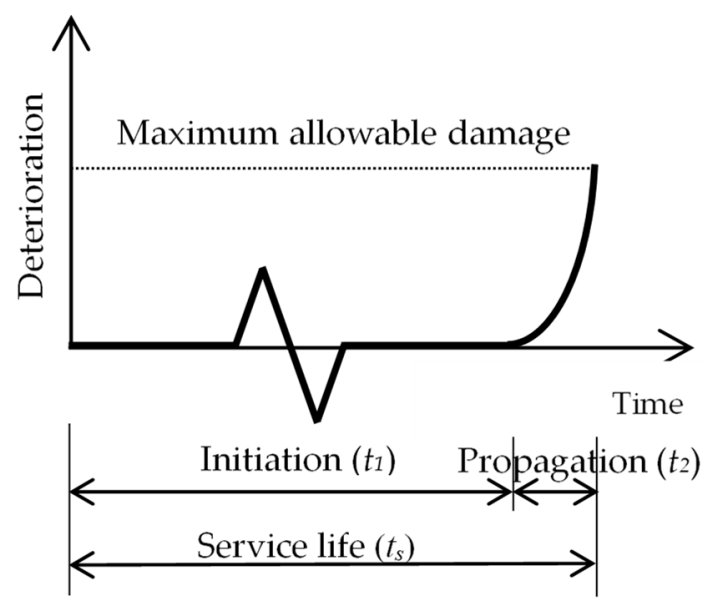

Figure 1. Phases in the service life of a RC structure.

\section{Service Life Prediction Models}

\subsection{Effects of Temperature}

Under different ambient temperatures, the kinematic performance of corrosive ions is variable. The relation between temperature and chloride penetration rate can be evaluated using a formula based on the Arrhenius' law, as shown in Equation (5), which is widely accepted by most references [6,26-28]:

$$
f_{T}(T)=\exp \left[\frac{U}{R}\left(\frac{1}{T_{0}}-\frac{1}{T}\right)\right],
$$

where $f_{T}(T)$ is the temperature factor, $U$ is the activation energy of the chloride diffusion process $(\mathrm{kJ} / \mathrm{mol}), R$ is the ideal gas constant $\left(8.31 \times 10^{-3} \mathrm{~kJ} / \mathrm{mol} / \mathrm{K}\right), T_{0}$ is the reference temperature $(\mathrm{K})$ and $T$ is the ambient temperature $(\mathrm{K})$.

In addition to its effect on the activation energy, temperature simultaneously influences the concentration of free chloride ions which can be converted from bound ions. Free chloride ions are mainly considered to be involved in corrosion instead of bound chloride $[10,17,25,28]$. The relationship among the total $\left(C_{t}\right)$, bound $\left(C_{b}\right)$ and free $\left(C_{f}\right)$ chloride concentrations in the concrete medium can be expressed as follows $[29,30]$ :

$$
C_{t}=C_{b}+w_{e} C_{f}
$$




$$
\frac{\partial C_{b}}{\partial C_{f}}=\alpha,
$$

where $w_{e}$ is the evaporable water content $\left(\mathrm{m}^{3}\right.$ pore solution $/ \mathrm{m}^{3}$ concrete) and $\alpha$ is defined as the slope of the corresponding chloride binding isotherm which represents equilibrium relations between free chlorides and bound chlorides specific to a given concrete medium. In this study, the relationship between bound and free chlorides is assumed to be linear and the chloride binding capacity is treated as constant at a given temperature. The two parameters have coupled effects on the chloride diffusion coefficient $(D)$ and can be shown as follows [6,28]:

$$
f_{w, \alpha}(w, \alpha)=\frac{1}{1+\frac{1}{w_{e}} \frac{\partial C_{b}}{\partial C_{f}}}=\frac{1}{1+\frac{\alpha}{w_{e}}}
$$

where $f_{w, \alpha}(w, \alpha)$ is the coupled effect factor and the evaporable water content $\left(w_{e}\right)$ can be estimated as follows: [31,32]

$$
\begin{gathered}
w_{e}=\frac{C k V_{m} h}{(1-k h)[1+(C-1) k h]} ; \\
C=\exp \left(\frac{855}{T}\right) ; \\
k=\frac{\left(1-1 / n_{w}\right) C-1}{C-1} ; \\
n_{w}=\left(2.5+\frac{15}{t_{e}}\right)(0.33+2.2 w / c) N_{c t} ; \\
V_{m}=\left(0.068-\frac{0.22}{t_{e}}\right)(0.85+0.45 w / c) V_{c t},
\end{gathered}
$$

where $C, k$ and $V_{m}$ are parameters depending on the temperature, water/cement ratio $(w / c)$ and the degree of hydration of concrete; $h$ is the humidity; $t_{e}$ is the hydration period (d); and $N_{c t}$ and $V_{c t}$ depend on the type of cement, e.g., for Portland cement II, $N_{c t}=V_{c t}=1$.

\subsection{Deterministic Model for Corrosion Initiation}

The material properties of concrete in an aggressive environment are not constant. The chloride diffusion coefficient decreases with time according to the following power law $[33,34]$ :

$$
f_{t}(t)=\left(\frac{t_{0}}{t}\right)^{m},
$$

where $f_{t}(t)$ is the ageing factor and $m$ is the decay rate.

In summary, the computational model of the chloride diffusion coefficient can be written as shown in Equation (15) by considering temperature and ageing effects:

$$
D=D_{0} f_{T} f_{w, \alpha} f_{t},
$$

where $D_{0}$ is diffusion coefficient at time $t_{0}$.

Equation (15) can be used to effectively predict the chloride diffusion coefficient at different ambient temperatures and times. Following this, the deterministic model can be obtained by substituting Equation (15) into Equation (3) and the chloride concentration at any point and time in concrete can be accurately obtained.

\subsection{Probabilistic Model for Corrosion Initiation}

Large research efforts have been made to predict the corrosion life with deterministic methods, however, the uncertainty of input variables, including the uncertainty of material properties and environmental conditions, can affect the corrosion process of RC 
piles $[3,16,27,35-37]$. Various parameters, such as the surface chloride content $\left(C_{s}\right)$ and diffusion coefficient $(D)$ and threshold value $\left(C_{t h}\right)$, were considered random variables in this paper. One of the aims of this paper is to propose a probabilistic model based on previous works. The analysis includes the randomness of parameters and the application of the Monte Carlo simulation. A total of $10^{6}$ sets of data are calculated. It is assumed that $F(t)$ is the difference between $C_{t h}$ and $C_{f_{s}}$ (chloride content at the steel surface at time $t$ ).

$$
F(t)=C_{t h}-C_{f_{s}} .
$$

The failure probability of corrosion initiation $P_{f}(t)$ and the corrosion initiation life $T_{i}$ can be estimated as follows.

$$
\begin{gathered}
P_{f}(t)=P[F(t) \leq 0]=P\left[C_{t h} \leq C_{f s}\right] ; \\
T_{i}=\left[P_{f}(t) \geq P_{f, \text { max }}\right] .
\end{gathered}
$$

CEB [38] proposed an intended $P_{f, \text { durability }}$ of $10 \%$ for RC structures exposed to chloride attacks. In this study, $10 \% P_{f}$ durability is applied as the limit state for the prediction.

\subsection{Prediction Model for Corrosion Propagation}

The time to corrosion propagation is viewed as the period from the chloride concentration reaching a critical value to the emergence of microcracks around rebars. The corrosion risk of rebar in RC structures can be determined in terms of current density if the passivation film is damaged. According to Faraday's law [39], the corrosion velocity can be expressed as the following:

$$
x_{i}=\frac{M i_{\text {corr }} t}{n \rho_{s} F}=2.949 \times 10^{-10} \int_{0}^{t} i_{\text {corr }}(t) d t,
$$

where $x_{i}$ is the reinforcement corrosive depth $(\mu \mathrm{m}), M$ is the molar mass of $\mathrm{Fe}, i_{\text {corr }}$ is the corrosive current density $\left(\mu \mathrm{A} / \mathrm{cm}^{2}\right), n$ is the charge of the reactive ion $(n=2.5$ in this paper), $\rho_{S}$ is the density of $\mathrm{Fe}\left(7.9 \mathrm{~g} / \mathrm{cm}^{3}\right), F$ is the Faraday constant $(96,500 \mathrm{C} / \mathrm{mol})$ and $t$ (years) is the time after corrosion initiation. Liu [10] proposed Equation (20) to demonstrate how $i_{\text {corr }}$ is influenced by temperature:

$$
i_{\text {corr }}=0.926 \exp \left[7.98+0.7771 \ln (1.69 C)-\frac{3006}{T}-1.664 R+2.24 t^{-0.215}\right],
$$

where $C$ is the chloride concentration on the reinforcement surface $\left(\mathrm{kg} / \mathrm{m}^{3}\right), T$ is the ambient temperature $(\mathrm{K})$ and $R$ is the ohmic resistance $(\Omega)$ of the concrete cover. For the ohmic resistance, $R$ can be calculated using the following empirical relationship suggested by Liu [40]:

$$
R=\exp [8.03-0.54 \ln (1+1.69 C)] .
$$

According to Equation (20), when the time $t$ is near zero, the current density is infinite and cannot be integrated. Thus, $t$ is calibrated based on the literature [3] and is shown as the following:

$$
i_{c o r r, 0}=\frac{37.8(1-w / c)^{-1.64}}{c},
$$

where $i_{c o r r}, 0$ is the corrosion rate at the start of corrosion propagation, $w / c$ is the water-tocement ratio and $c$ is the concrete cover $(\mathrm{cm})$. Therefore, Equation (20) can be expressed as follows:

$$
i_{\text {corr }}=0.926 \exp \left[7.98+0.7771 \ln (1.69 C)-\frac{3006}{T}-1.664 R+2.24(t+0.1)^{-0.215}\right] .
$$


As time elapses, corrosion products continue to accumulate, which leads to an increase in expansion stress. Once the corrosion depth $\left(x_{i}\right)$ of the reinforcement reaches the critical depth $\left(x_{c r}\right)$, the cracking of the pile concrete occurs. The critical corrosion depth $x_{c r}$ can be calculated as follows [35]:

$$
x_{c r}=\frac{r_{0}}{\alpha_{v}-1}\left[\frac{2 c\left(\gamma+1+v_{c}\right)}{d_{0}} \frac{f_{c t}}{E_{e f}}+\frac{\delta_{0}}{r_{0}}\right],
$$

where $\delta_{0}$ is the tiny spacing between the concrete and steel bar $(\mu \mathrm{m}), r_{0}=\delta_{0}+d_{0} / 2, d_{0}$ is the initial diameter of the reinforcement $(\mathrm{mm}), \alpha_{v}$ is the relative volume expansion ratio of rust, $c$ is the thickness of the cover $(\mathrm{mm}), \gamma=2 r_{0}^{2} /\left[c\left(2 r_{0}+c\right)\right], v_{c}$ is Poisson's ratio of the concrete, $f_{c t}$ is the tensile strength of the concrete $(\mathrm{MPa})$; and $E_{e f}=E_{c} /\left(1+\varphi_{c}\right)$, in which $E_{c}$ is the modulus of elasticity of the concrete $(\mathrm{MPa})$ and $\varphi_{c}$ is the creep coefficient of the concrete. The time to corrosion propagation can be obtained by equating the reinforcement corrosive depth $\left(x_{i}\right)$ to the critical depth $\left(x_{c r}\right)$.

\section{Illustrative Example}

\subsection{Time to Corrosion Initiation Using the Deterministic Method}

Some assumptions should be cleared in using the predictive model to evaluate the service life of piles. The RC pile has been immersed in marine environments at a constant temperature for 60 years and five levels of temperature are considered $\left(10^{\circ} \mathrm{C}, 20^{\circ} \mathrm{C}, 30^{\circ} \mathrm{C}\right.$, $40{ }^{\circ} \mathrm{C}$ and $50{ }^{\circ} \mathrm{C}$ ). The surface chloride content $\left(C_{S}\right)$ is $0.5 \%$ (\% by weight of concrete). The section size of the square pile is $500 \times 500 \mathrm{~mm}^{2}$, the diameter of the steel bars $(d)$ is $14 \mathrm{~mm}$ and the thickness of the concrete cover $(c)$ is $50 \mathrm{~mm}$ (see Figure 2). The water-to-cement ratio $(w / c)$ is 0.4 . On the basis of temperature variations the values of $\alpha$ are different, as shown in Table 1 . Assuming that all chloride ions come from the outside, the initial chloride concentration $\left(C_{0}\right)$ in concrete is zero. When the chloride concentration on the surface of the steel bar reaches the chloride ion threshold $\left(C_{t h}\right)$, the time of the first phase $\left(t_{1}\right)$ can be computed. Table 1 shows variables for calculations of chloride content $(C)$ and initiation time $\left(t_{1}\right)$. The steel bar (marked in blue) in the upper left corner of Figure 2 is about to be taken for prediction.

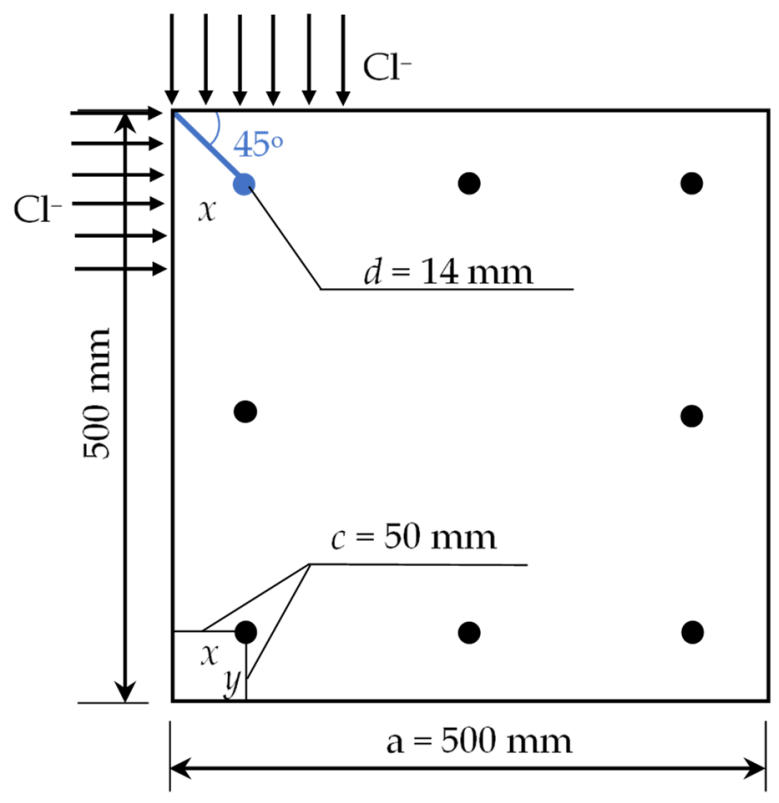

Figure 2. Configuration of RC square pile.

Figure 3 illustrates the influence of temperature on the chloride concentration at the steel surface, i.e., the higher the temperature is, the higher the concentration. The corrosion rate is slower at the beginning and then it becomes faster and eventually tends to 
become stable, especially for higher temperature conditions. When the chloride content increases to $C_{t h}(0.2 \%)$, it can be argued that the lifetime $\left(t_{1}\right)$ of the pile alongside the passive layer of steel is destroyed. Under the conditions of $30{ }^{\circ} \mathrm{C}, 40{ }^{\circ} \mathrm{C}$ and $50{ }^{\circ} \mathrm{C}$, the service life of the pile is 60 years, 28.8 years and 14.5 years, respectively. However, in colder environments, the steel passivation film has not been damaged for 60 years. Without any protection measures applied to reinforcements, higher temperatures lead to shorter life spans. Therefore, for RC piles served at high temperatures, such as those of tropical marine regions; anti-corrosion measures, such as cathode protection; and corrosion inhibitors should be applied to prolong lifetimes.

Table 1. Variables in $t_{1}$ computation.

\begin{tabular}{ccc}
\hline Variable & Description & Value \\
\hline$C_{0}$ & Initial chloride concentration in & 0 \\
$C_{s}$ & concrete & $0.5 \%[35]$ \\
$C_{t h}$ & Concrete surface chloride concentration & $0.2 \%[35]$ \\
$U$ & The threshold concentration & $41.8 \mathrm{~kJ} / \mathrm{mol}[25]$ \\
$R$ & Activation energy & $8.31 \times 10^{-3} \mathrm{~kJ} / \mathrm{mol} / \mathrm{K}[25]$ \\
$D_{0}$ & Ideal gas constant & $5.98 \times 10^{-12} \mathrm{~m}^{2} / \mathrm{s}[36]$ \\
$t_{0}$ & Diffusion coefficient at time $t_{0}(28 \mathrm{~d})$ & $28 \mathrm{~d}$ \\
$\alpha$ & Time for standard curing of concrete & $0.6,0.8,1.0,0.93,0.85[6]$ \\
$h$ & $\partial C_{b} / \partial C_{f}$ & 1 \\
$t_{e}$ & Humidity of pore in concrete & $60 \times 365 \mathrm{~d}$ \\
$m$ & Hydration period & $0.2[16,34]$ \\
$x, y=c$ & The decay rate & $0.05 \mathrm{~m}$ \\
\hline
\end{tabular}

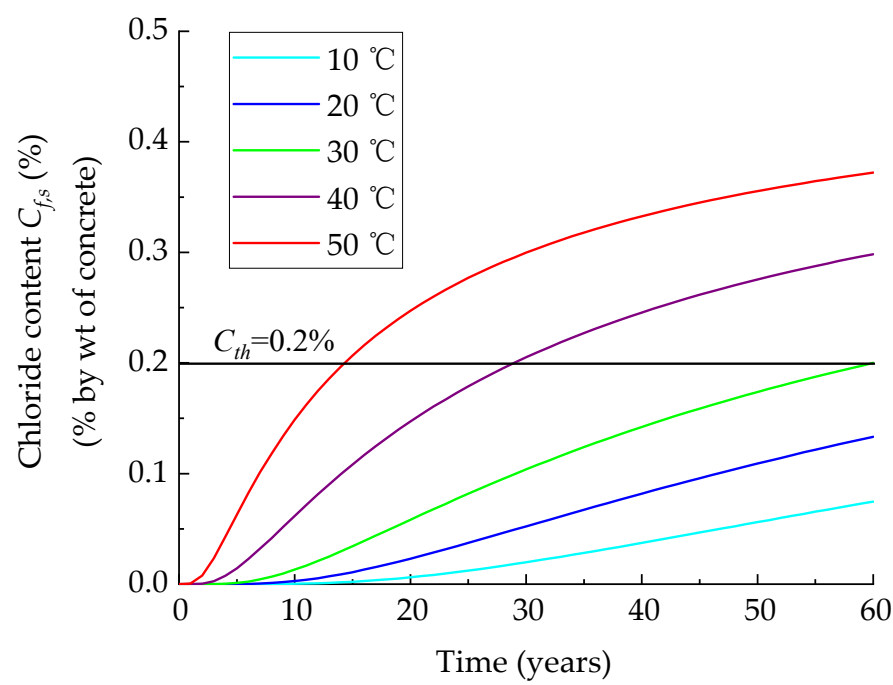

Figure 3. Relation between chloride content $(C)$ at the steel surface and exposure time $(t)$.

Figure 4 presents the chloride concentration distribution along the $45{ }^{\circ} \mathrm{C}$ line. The content decreases increasing depth, especially at low temperatures. After an exposure time of 60 years, the distribution characteristics verify that high temperature can strengthen chloride attacks. When $x=50 \mathrm{~mm}$, the chloride content at $50{ }^{\circ} \mathrm{C}$ is five times of that at $10^{\circ} \mathrm{C}$.

\subsection{Time to Corrosion Initiation Using the Probabilistic Method}

The distribution, mean and coefficient of variation (COV) of random variables are presented in Table 2. Figure 5 indicates the variation in the failure probability of corrosion initiation with exposure time, confirming that high temperatures can pose a threat to the service life of piles. According to the criterion [38] $\left(P_{f, \max }=10 \%\right)$, when the temperature 
level is $30{ }^{\circ} \mathrm{C}, 40{ }^{\circ} \mathrm{C}$ and $50{ }^{\circ} \mathrm{C}$, the corrosion initiation times $\left(t_{1}\right)$ of the pile are 51.3, 25.3 and 12.7 years, respectively. The figure shows that for piles constructed in hightemperature areas, the failure probability will soar sharply to a high level in the next few years. Compared with the deterministic model, the results derived from the probabilistic method are conservative. Under the boundary condition of $20^{\circ} \mathrm{C}$, the RC pile has not corroded for 60 years and $P_{f}$ is less than $0.15 \%$. In addition, the failure probability at $10{ }^{\circ} \mathrm{C}$ has always been in a very low state, which is close to zero.

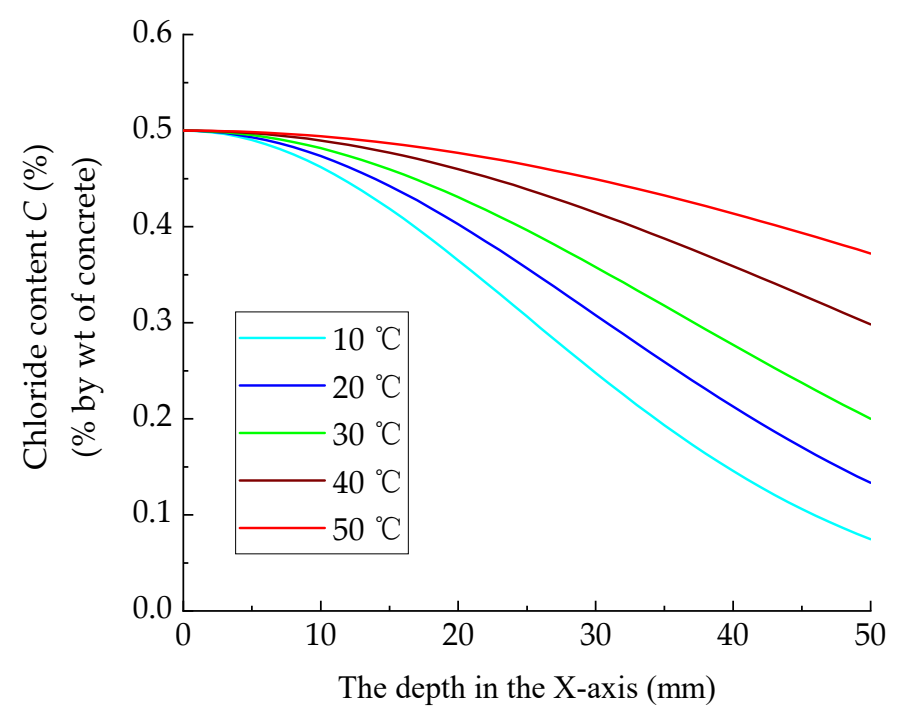

Figure 4. Chloride content distribution in concrete for an exposure time of 60 years.

Table 2. Probabilistic models of main random variables.

\begin{tabular}{cccc}
\hline Variable & Distribution & Mean & COV \\
\hline$C_{S}$ & Normal [35] & $0.5 \%$ & 0.1 \\
$C_{t h}$ & Uniform [3,27] & $0.2 \%$ & 0.19 \\
$D_{0}$ & Normal [35] & $5.98 \times 10^{-12} \mathrm{~m}^{2} / \mathrm{s}$ & 0.1 \\
\hline$T$ & Normal [37] & $10,20,30,40,50^{\circ} \mathrm{C}$ & 0.1 \\
$m$ & Normal [37] & 0.2 & 0.2 \\
\hline
\end{tabular}

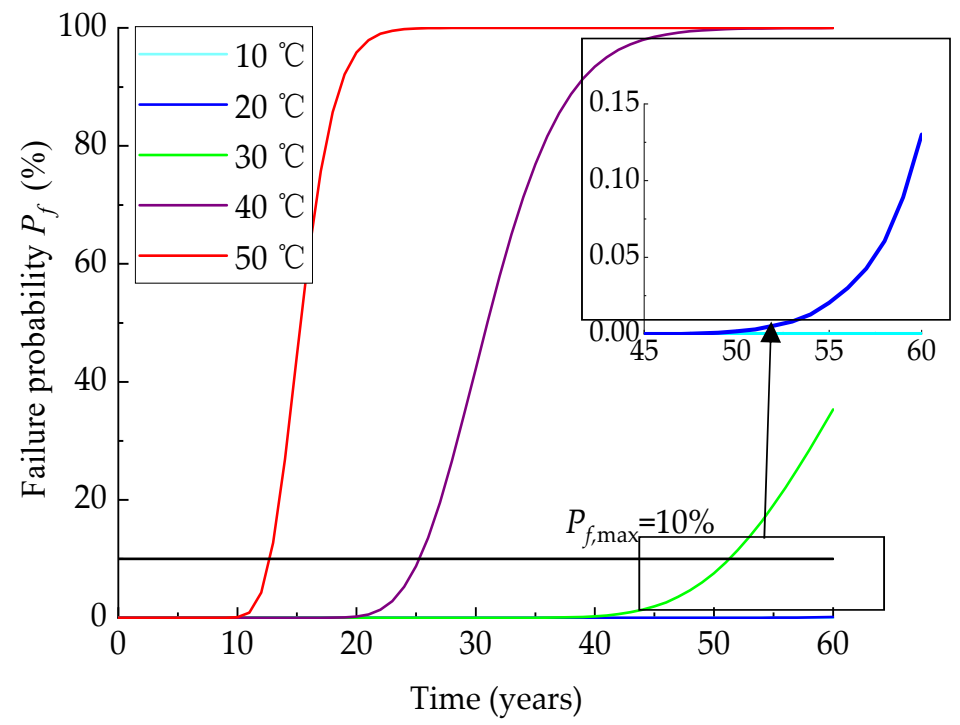

Figure 5. Variation in the failure probability of the corrosion initiation with exposure time. 


\subsection{Time to Corrosion Propagation}

Variables involved in $t_{2}$ computation are displayed in Table 3. Figure 6 illustrates the variation in the reinforcement corrosive depth $\left(x_{i}\right)$ during corrosion propagation. All curves were highly similar: the slopes of the curves decreased and gradually remained constant because the corrosive current density $\left(i_{\text {corr }}\right)$ tended to be stable with time. The corrosion propagation time $\left(t_{2}\right)$ of the pile is 0.18 years, 0.11 years, 0.07 years, 0.05 years and 0.03 years with temperature levels of $10^{\circ} \mathrm{C}, 20^{\circ} \mathrm{C}, 30^{\circ} \mathrm{C}, 40^{\circ} \mathrm{C}$ and $50^{\circ} \mathrm{C}$, respectively. The results hint that the corrosive depth would reach the critical value quickly even at lower temperatures. Therefore, compared with the initiation time, the propagation phase is much shorter and may be ignored in lifetime predictions [18].

Table 3. Variables in $t_{2}$ Computation.

\begin{tabular}{ccc}
\hline Variable & Description & Value \\
\hline$M$ & Molar mass of Fe & $5.6 \mathrm{~g} / \mathrm{mol}$ \\
$n$ & Charge of reactive ion & $2.5[39]$ \\
$\rho_{s}$ & Density of Fe & $7.9 \times 10 \mathrm{~kg} / \mathrm{m}^{3}$ \\
$C$ & Chloride ion threshold & $4.8 \mathrm{~kg} / \mathrm{m}^{3}\left(C_{t h}=0.5 \%\right)$ \\
$d_{0}$ & Diameter of steel & $14 \mathrm{~mm}$ \\
$c$ & Thickness of cover & $50 \mathrm{~mm}$ \\
$\alpha_{v}$ & Relative volume expansion ratio & $3[4]]$ \\
$v_{c}$ & Poisson's ratio of the concrete & $0.2[27]$ \\
$f_{c t}$ & Tensile strength of the concrete & $2.39 \mathrm{MPa}$ \\
$E_{c}$ & Modulus of elasticity of the concrete & $3.25 \times 10^{4} \mathrm{MPa}$ \\
$\varphi_{c}$ & Creep coefficient of concrete & 2 \\
\hline
\end{tabular}

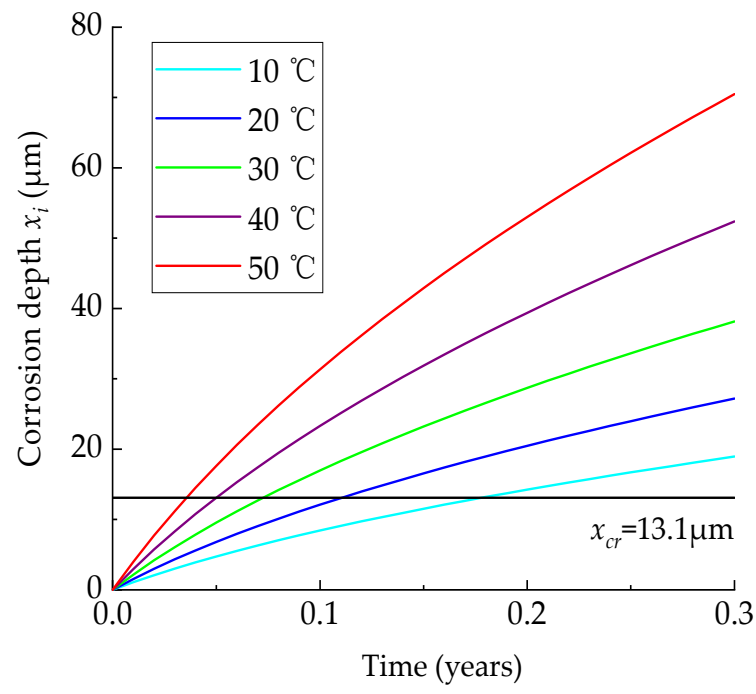

Figure 6. Corrosive depth $x_{i}$ in different temperatures.

\section{Lateral Bearing Capacity Analysis of Piles}

\subsection{Performance Fuctions}

In addition to the abovementioned assumptions, other practical field data must be considered in analytical solutions. It is assumed that the pile is fully embedded in a normally consolidated marine clay and subjected to horizontal loading $\left(H_{0}\right)$, vertical loading $\left(N_{0}\right)$ and moment loading $\left(M_{0}\right)$ at the pile head (shown in Figure 7). The length of the pile under the soil is $20 \mathrm{~m}$ and the proportional factor $\left(k_{h}\right)$ of the coefficient of the subgrade reaction is $3.0 \mathrm{MN} / \mathrm{m}^{4}$ [42]. Using the subgrade reaction theory proposed by Poulos [42], the governing equation for the deflection of a laterally loaded pile is

$$
E_{p} I_{p} \frac{d^{4} x}{d z^{4}}+k_{h} a x=0,
$$


where $E_{p}$ is the modulus of elasticity of the pile (MPa), $I_{p}$ is the moment of inertia of the pile section $\left(\mathrm{m}^{4}\right)$ and $a$ is the side length of the section (m). The solutions to Equation (25) are most conveniently obtained using a numerical finite-difference method.

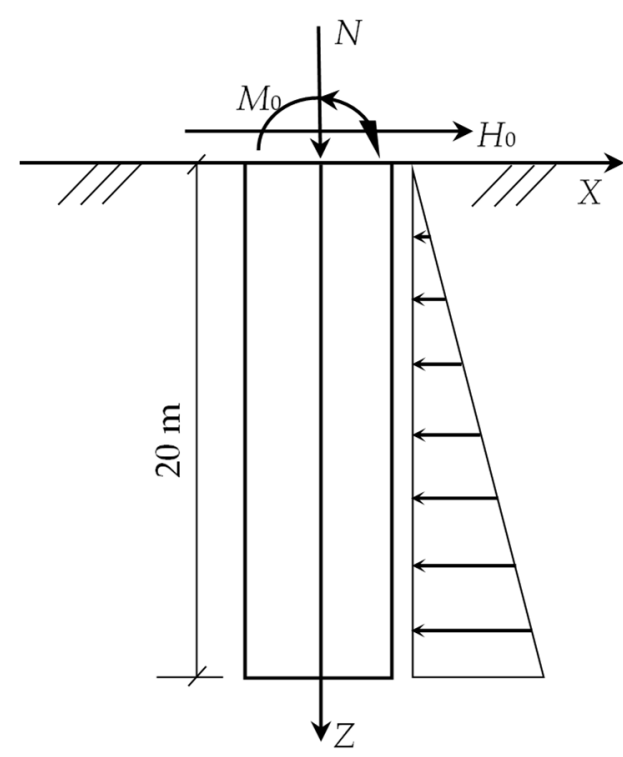

Figure 7. Schematic diagram of a single pile and loadings.

Chloride ions can permeate into concrete, triggering steel corrosion and leading to the reduction in structural capacity and loss of durability. Thus, the degradation coefficient $(\eta)$ should be introduced to modify the time-dependent pile stiffness, as shown in the following:

$$
E_{p} I_{p}=\eta E_{c} I_{p},
$$

where $\eta$ is determined by each RC pile. DEC [42] suggests that the degradation coefficient be expressed as follow:

$$
\eta=\frac{1}{A} \sum \eta_{i} A_{i}
$$

where $A$ is the sum of the sectional area of the tensile steel bar before corrosion $\left(\mathrm{m}^{2}\right), A_{i}$ is the sectional area of the $i_{\text {th }}$ steel bar after corrosion $\left(\mathrm{m}^{2}\right)$ and $\eta_{i}$ is the stiffness degradation coefficient of the $i_{t h}$ steel bar that can be computed by the following:

$$
\eta_{i}=\left\{\begin{array}{cc}
1.0 & 0 \leq x_{i}<0.1 \\
\left(3.7-7 x_{i}\right) & 0.1 \leq x_{i}<0.25 \\
0.65 & 0.25 \leq x_{i}
\end{array}\right.
$$

The exposure time of 40 years is taken for analysis in this section. Based on the results calculated above, we know that the RC square pile constructed at $40{ }^{\circ} \mathrm{C}$ has experienced corrosion initiation for 28.8 years and the reinforcement corrosive depth $\left(x_{i}\right)$ has developed for 11.2 years. Thus, the $\eta$ value of the pile is available and is shown in Table 4. Other data regarding piles served in different temperature conditions can also be obtained. Table 5 shows variables involved in the analysis of the behaviour of laterally loaded piles.

Table 4. Degradation coefficient of piles in service for 40 years.

\begin{tabular}{ccccccc}
\hline $\begin{array}{c}\text { Temperature } \\
\left({ }^{\circ} \mathbf{C}\right)\end{array}$ & $\begin{array}{c}\text { Time to Initiation } \\
\text { (yrs) }\end{array}$ & $\begin{array}{c}\text { Time to } \boldsymbol{x}_{\boldsymbol{i}} \\
\text { (yrs) }\end{array}$ & $\boldsymbol{x}_{\boldsymbol{i}} \mathbf{( \mathbf { m m } )}$ & $\begin{array}{c}\boldsymbol{A}_{\boldsymbol{i}} \\
(\mathbf{m m} \mathbf{2})\end{array}$ & $\eta_{\boldsymbol{i}}$ & $\boldsymbol{\eta}$ \\
\hline $10,20,30^{\circ} \mathrm{C}$ & 40 & 0 & 0 & & 1 & 1 \\
$40^{\circ} \mathrm{C}$ & 28.8 & 11.2 & 0.51 & $42.12 \times \mathrm{pi}$ & 0.65 & 0.56 \\
$50^{\circ} \mathrm{C}$ & 14.5 & 25.5 & 1.18 & $33.87 \times \mathrm{pi}$ & 0.65 & 0.45 \\
\hline
\end{tabular}


Table 5. Initial stress state and basic characteristics of piles.

\begin{tabular}{ccc}
\hline Variable & Description & Value \\
\hline$H_{0}$ & Horizontal load & $200 \mathrm{kN}$ \\
$N_{0}$ & Vertical load & $2000 \mathrm{kN}$ \\
$M_{0}$ & Moment & $300 \mathrm{kNm}$ \\
$k_{h}$ & Proportional factor of the coefficient of the subgrade reaction & $3.0 \mathrm{MN} / \mathrm{m}^{4}$ \\
$E_{c}$ & Modulus of elasticity of the concrete & $3.25 \times 10^{4} \mathrm{MPa}$ \\
$I_{p}$ & Moment of inertia of pile section & $0.5^{4} / 12 \mathrm{~m}^{4}$ \\
\hline
\end{tabular}

\subsection{Bearing Capacity Analysis}

In this section, the main focus is on working on variations in the performance of piles after the service time reaches 25 years. Figure 8 shows the variation in the degradation coefficient of the pile stiffness with exposure time at different temperatures. Since the degradation coefficients $(\eta)$ of structures are identical at $10^{\circ} \mathrm{C}, 20^{\circ} \mathrm{C}$ and $30^{\circ} \mathrm{C}$, only the performance at $30^{\circ} \mathrm{C}$ is exhibited for comparison. At $30^{\circ} \mathrm{C}, \eta$ remains constant at all times because the time to corrosion initiation is more than 40 years and the steel does not rust. At $40{ }^{\circ} \mathrm{C}$ and $50{ }^{\circ} \mathrm{C}$, two distinct descending segments emerge after corrosion initiation. The first dropping phase is sharper because $\eta_{i}$ and $A_{i}$ are degressive (based on Equation (27)). Then, the reduction speed of the degradation coefficient slows down only because of a decrease in $A_{i}$.

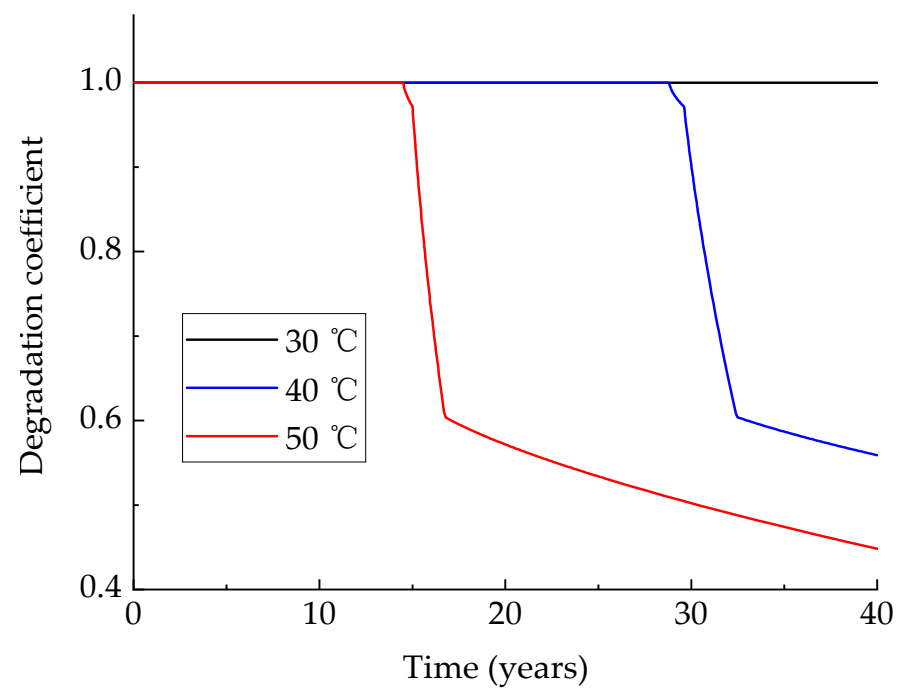

Figure 8. Variations in the degradation coefficient with time.

Figure 9 shows the shear force, displacement and bending moment distribution along the pile as the temperature increases from $30^{\circ} \mathrm{C}$ to $50{ }^{\circ} \mathrm{C}$. The shear force distributions of the piles at various temperatures are indicated in Figure 9a. Affected by the lateral resistance from the soil, the shear forces of the piles decrease from $200 \mathrm{kN}$ to $0 \mathrm{kN}$ at approximately $-2 \mathrm{~m}$ and the maximum negative shear forces are $-82.4,-88.9$ and $-93.7 \mathrm{kN}$.

The horizontal displacement distributions of the piles are shown in Figure 9b. The maximum displacements appear at the top of the piles and are $50 \mathrm{~mm}, 62 \mathrm{~mm}$ and $67 \mathrm{~mm}$. The maximum rate of increase is $34 \%$. The "zero point" of displacement shifts from $-5 \mathrm{~m}$ to $-4 \mathrm{~m}$ as the temperature increases and this implies a reduction in the stability of the pile.

Figure $9 \mathrm{c}$ shows the bending moment distribution of the piles. The bending moment reaches its maximum when the depth is approximately $2 \mathrm{~m}$. At this point, the moments of $40{ }^{\circ} \mathrm{C}$ and $50{ }^{\circ} \mathrm{C}$ decrease by $5 \%$ and $7 \%$, respectively, compared with those of the pile without rust damage. As the embedded depth increases, the moments begin to decrease and a negative moment region appears at $10 \mathrm{~m}$ of depth. Finally, the bending moments 
disappear. The drawing shows that the higher the temperature is, the smaller the bending moment value.

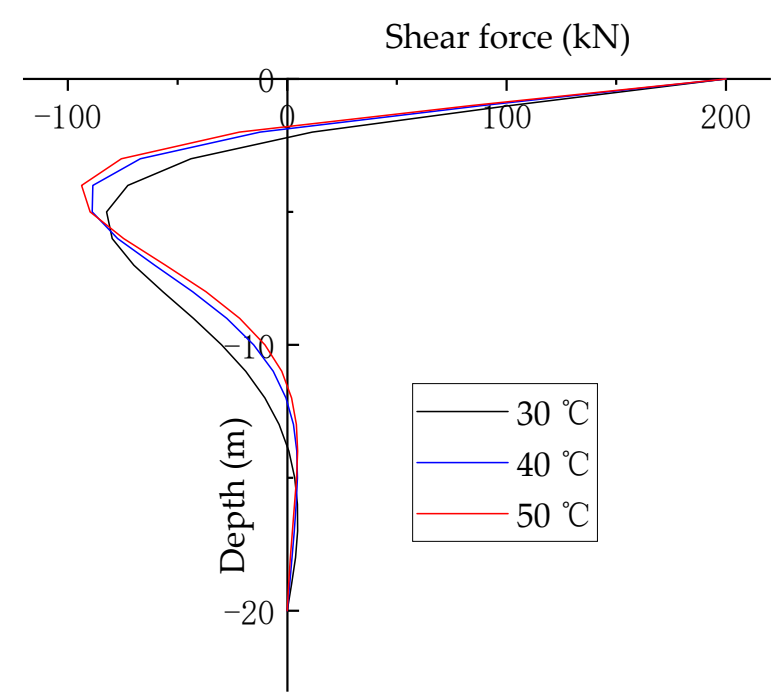

(a)

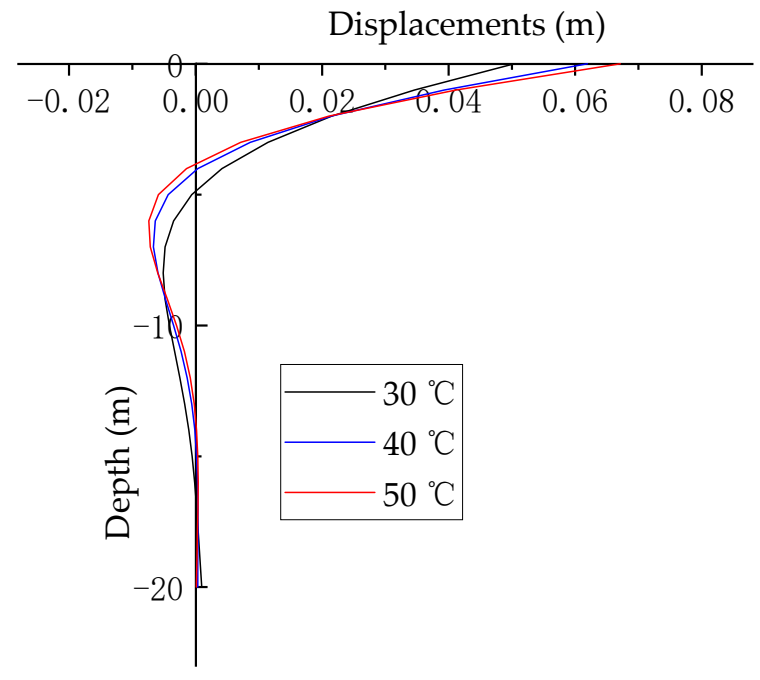

(b)

Bending moments $(\mathrm{kN} \cdot \mathrm{m})$

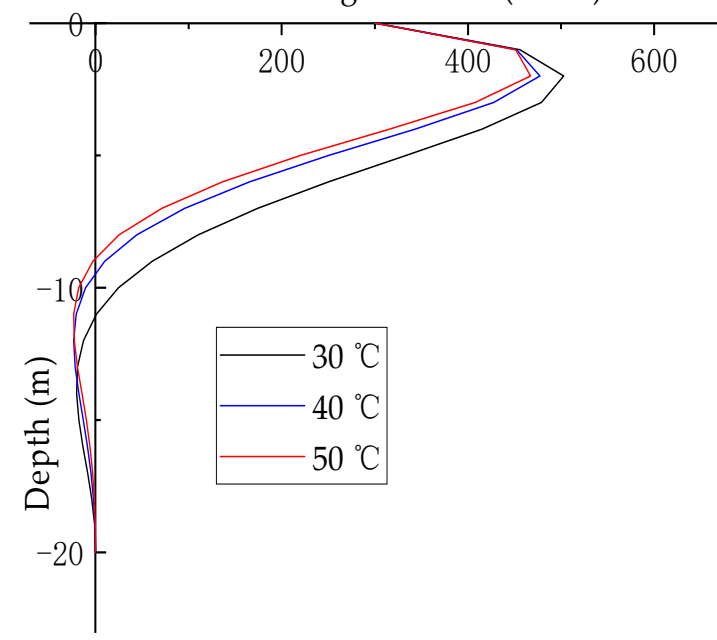

(c)

Figure 9. Internal force distribution diagrams of piles: (a) shear force; (b) displacement; (c) bending moment.

\section{Conclusions}

This paper focuses on predicting the service life of piles affected by chloride ingress and varying temperatures. The lifespan is usually defined as the sum of the times to corrosion initiation and propagation. A deterministic method is proposed on the basis of Fick's second law combined with temperature and ageing factors. Due to the randomness of the material and environment in the actual situation, a probabilistic model is applied to study the reliability of RC piles. Chloride concentration distribution curves and the service life of piles can be obtained by predictive models. The stiffness degradation coefficient is introduced to assess variations in the lateral bearing capacity characteristics of piles. The coefficient is severely affected by temperature, which can enhance the current density and boost corrosion products, leading to the cracking of the pile. Diagrams of the shear force, bending displacement and moment of piles are drawn in this paper.

The main conclusions of the present study are as follows:

1. Temperature has substantial influences on the activation energy, evaporable water content and ratio of binding capacity. These parameters can change the chloride 
diffusion rate which imposes a threat on the service life of RC piles. The steel surface chloride content at $50{ }^{\circ} \mathrm{C}$ is 5 -fold of that at $10^{\circ} \mathrm{C}$;

2. The probabilistic method is conservative compared to the deterministic method. Compared with the time to corrosion initiation, the time to propagation is much shorter;

3. High temperatures can intensify the current density, which determines the corrosion rate of the reinforcement. The stiffness degradation coefficient of the pile is highly influenced by the reinforcement corrosive depth. The coefficient decreases rapidly when the protective layer of the reinforcing steel is destroyed.

4. The behaviour of laterally loaded piles in chloride environments is analysed based on the stiffness degradation coefficient from the perspectives of the shear force, displacement and bending moment of piles.

Author Contributions: Conceptualization, Y.L. and Y.C.; data curation, Y.L.; formal analysis, Y.L.; investigation, Y.L.; funding acquisition, W.S. and J.Z.; methodology, Y.L. and W.S.; resources, Y.C. and W.S.; software, Y.L.; supervision, Y.C., W.S., J.Z., S.L. and T.M.F.-S.; validation, Y.C. and W.S.; visualization, Y.L.; writing-original draft, Y.L.; review and editing, S.L. and T.M.F.-S. All authors have read and agreed to the published version of the manuscript.

Funding: This research was financially supported by the National Natural Science Foundation of China (Grant Nos. 52078289 and 41372319) and the Innovation Program of Shanghai Municipal Education Commission, China (Grant No. 15ZZ081).

Institutional Review Board Statement: Not applicable.

Informed Consent Statement: Not applicable.

Data Availability Statement: Not applicable.

Conflicts of Interest: The authors declare no conflict of interest.

\section{References}

1. Tang, L.; Utgenannt, P.; Boubitsas, D. Durability and Service Life Prediction of Reinforced Concrete Structures. In Proceedings of the 14th International Congress on the Chemistry of Cement, Beijing, China, 13 October 2015.

2. Weerdt, K.D.; Lothenbach, B.; Geiker, M.R. Comparing Chloride Ingress from Seawater and NaCl Solution in Portland Cement Mortar. Cem. Concr. Res. 2019, 115, 80-89. [CrossRef]

3. Kim, A.T.V.; Mark, G.S. Structural Reliability of Concrete Bridges Including Improved Chloride Induced Corrosion Models. Struct. Saf. 2000, 22, 313-333. [CrossRef]

4. Yu, C.W.; Bull, J.W. Durability of Materials and Structures in Building and Civil Engineering, 1st ed.; CRC Press: Boca Raton, FL, USA, 2006.

5. Jiang, L.H.; Li, C.Z.; Zhu, C.L.; Song, Z.J.; Chu, H.Q. The Effect of Tensile Fatigue on Chloride Ion Diffusion in Concrete. Constr. Build. Mater. 2017, 151, 119-126. [CrossRef]

6. Shao, W.; Li, J.P.; Liu, Y. Influence of Exposure Temperature on Chloride Diffusion into RC Pipe Piles Exposed to Atmospheric Corrosion. J. Mater. Civ. Eng. 2016, 28, 1-8. [CrossRef]

7. Apostolopoulos, C.A.; Papadakis, V.G. Consequences of Steel Corrosion on the Ductility Properties of Reinforcement Bar. Constr. Build. Mater. 2008, 22, 2316-2324. [CrossRef]

8. Isteita, M.; Xi, Y. The Effect of Temperature Variation on Chloride Penetration in Concrete. Constr. Build. Mater. 2017, 156, 73-82. [CrossRef]

9. Hussain, S.E.; Rasheeduzzafar; Al-Musallam, A.; Al-Gahtani, A.S. Factors Affecting Threshold Chloride for Reinforcement Corrosion in Concrete. Cem. Concr. Res. 1995, 25, 1543-1555. [CrossRef]

10. Liu, T.; Weyers, R.W. Modeling the Dynamic Corrosion Process in Chloride Contaminated Concrete Structures. Cem. Concr. Res. 2019, 28, 365-379. [CrossRef]

11. Daniel, P.; Daniel, B.; Paul, M.; Kelly, J. Investigation and Initial Stability Analysis of a Wharf on Severely Deteriorated Steel H-Piles. In Proceedings of the American Society of Civil Engineers 15th Triennial International Conference, Pittsburgh, PA, USA, 15 September 2019; pp. 273-283. [CrossRef]

12. Cui, X.Z.; Zhang, N.; Li, S.C.; Zhang, J.; Tang, W.Z. Deterioration of Soil-Cement Piles in a Saltwater Region and Its Influence on the Settlement of Composite Foundations. J. Perform. Constr. Fac. 2014, 04014195. [CrossRef]

13. Tuutti, K. Swedish Foundation for Concrete Research Stockholm. In Corrosion of Steel in Concrete; CBI: Stockholm, Sweden, 1982; pp. 105-119.

14. Amey, S.L.; Johnson, D.A.; Miltenberger, M.A.; Farzam, H. Predicting the Service Life of Concrete Marine Structures: An Environmental Methodology. ACI Struct. J. 1998, 95, 205-214. 
15. Bhaskar, S.; Radhakrishna, G.P.; Ravindra, G.; Bharatkumar, B.H.; Iyer, N.R. Use of Portland Pozzolana Cement to Enhance the Service Life of Reinforced Concrete Exposed to Chloride Attack. J. Mater. Civ. Eng. 2015, 27, 04015031. [CrossRef]

16. Kwon, S.J.; Na, U.J.; Sang, S.P.; Sang, H.J. Service Life Prediction of Concrete Wharves with Early-aged Crack: Probabilistic Approach for Chloride Diffusion. Struct. Saf. 2009, 31, 75-83. [CrossRef]

17. Jee, A.A.; Pradhan, B. Study on Development of Empirical Relationships Between Durability Parameters of Concrete Made with Different Types of Binder and Exposed to Chloride Environment. Constr. Build. Mater. 2019, 212, 799-817. [CrossRef]

18. Khaghanpour, R.; Dousti, A.; Shekarchi, M. Prediction of Cover Thickness Based on Long-term Chloride Penetration in a Marine Environment. J. Perform. Constr. Fac. 2016, 31, 04016070. [CrossRef]

19. Zhou, A.; Qin, R.; Chow, C.L.; Lau, D. Structural Performance of FRP Confined Seawater Concrete Columns under Chloride Environment. Compos. Struct. 2019, 216, 12-19. [CrossRef]

20. Wang, Y.Z.; Liu, C.X.; Li, Q.M.; Wu, L.J. Chloride Ion Concentration Distribution Characteristics within Concrete Covering-layer Considering the Reinforcement Bar Presence. Ocean Eng. 2019, 173, 608-616. [CrossRef]

21. Shao, W.; Li, J.P. Service Life Prediction of Cracked RC Pipe Piles Exposed to Marine Environments. Constr. Build. Mater. 2014, 64, 301-307. [CrossRef]

22. Shao, W.; Shi, D.D.; Jiang, J.P.; Chen, Y.L. Time-dependent Lateral Bearing Behaviour of Corrosion-damaged RC Pipe Piles in Marine Environments. Constr. Build. Mater. 2017, 157, 676-684. [CrossRef]

23. Collepardi, M.; Marcialis, A.; Turrizzani, R. The Kinetics of Penetration of Chloride Ions into the Concrete. Ind. Ital. Cem. 1970, 4, 157-164.

24. Collepardi, M.; Marcialis, A.; Turrizzani, R. Penetration of Chloride Ions into Cement Pastes and Concretes. J. Am. Ceram. Soc. 1972, 55, 534-535. [CrossRef]

25. Enrico, Z.; Caio, G.N. Chloride Diffusion Assessment in RC Structures Considering the Stress-strain State Effects and Crack Width Influences. Constr. Build. Mater. 2019, 201, 100-109. [CrossRef]

26. Philip, V.H.; Michel, D.K.; Alice, E.; Annemie, A.; Nele, D.B. Service Life and Global Warming Potential of Chloride Exposed Concrete with High Volumes of Fly Ash. Cement Concrete Comp. 2017, 80, 210-223. [CrossRef]

27. Emilio, B.A.; Philippe, B.; Alaa, C. Probabilistic Lifetime Assessment of RC Structures under Coupled Corrosion-fatigue Deterioration Processes. Struct. Saf. 2009, 31, 84-96. [CrossRef]

28. Panesar, D.K.; Chidiac, S.E. Effect of Cold Temperature on the Chloride-Binding Capacity of Cement. J. Cold Reg. Eng. 2011, 25, 133-144. [CrossRef]

29. Martin, P.B.; Zibara, H.; Hooton, R.D.; Thomas, M.D.A. A Study of the Effect of Chloride Binding on Service Life Predictions. Cem. Concr. Res. 2000, 30, 1215-1223. [CrossRef]

30. Shazali, M.A.; Rahman, M.K.; Al-Gadhib, A.H.; Baluch, M.H. Transport Modeling of Chlorides with Binding in Concrete. Arab. J. Sci. Eng. 2012, 37, 469-479. [CrossRef]

31. Brunauer, S.; Skalny, J.; Bodor, E. Adsorption on Non-porous Solids. J. Colloid Interface Sci. 1969, 30, 546-552. [CrossRef]

32. Xi, Y.; Bazant, Z.; Jennings, H. Moisture Diffusion in Cementitious Materials-adsorption Isotherms. Adv. Cem. Based Mater. 1994, 1, 248-257. [CrossRef]

33. Karolina, H.; Šmilauer, V.; Libor, J. Prediction of Reinforcement Corrosion Due to Chloride Ingress and its Effects on Serviceability. Eng. Struct. 2018, 174, 768-777. [CrossRef]

34. Petcherdchoo, A.; Chindaprasirt, P. Exponentially Aging Functions Coupled with Time-dependent Chloride Transport Model for Predicting Service Life of Surface-treated Concrete in Tidal Zone. Cem. Concr. Res. 2019, 120, 1-12. [CrossRef]

35. Shao, W.; Nie, Y.H.; Liang, F.Y.; Shi, D.D. A Novel Comprehensive Evaluation Method for the Corrosion Initiation Life of RC Hollow Piles in Chloride Environments. Constr. Build. Mater. 2020, 249, 118801. [CrossRef]

36. Zheng, J.J.; Zhang, J.; Zhou, X.Z.; Wu, Y.F.; Ye, Y.M.; Wang, Y.H. A Three-step Analytical Scheme for Estimating the Steady-state Chloride Diffusion Coefficient of Mature Cement Paste. Constr. Build. Mater. 2018, 191, 1004-1010. [CrossRef]

37. Xu, Q.H.; Shi, D.D.; Shao, W. Service Life Prediction of RC Square Piles Based on Time-varying Probability Analysis. Constr. Build. Mater. 2019, 227, 116824. [CrossRef]

38. Comité Euro-International Du Béton (CEB). CEB-FIP Model Code for Service Life Design; The International Federation for Structural Concrete (FIB): Lausanne, Switzerland, 2006.

39. Du, F.Y.; Jin, Z.Q.; She, W.; Xiong, C.S.; Feng, G.G.; Fan, J.F. Chloride Ions Migration and Induced Reinforcement Corrosion in Concrete with Cracks: A Comparative Study of Current Acceleration and Natural Marine Exposure. Constr. Build. Mater. 2020, 263, 120099. [CrossRef]

40. Liu, Y.P. Modeling the Time-to-corrosion Cracking of the Cover Concrete in Chloride Contaminated Reinforced Concrete Structures. ACI Mater. J. 1996, 95, 675-681. [CrossRef]

41. Poulos, H.G.; Davis, E.H. Pile Foundation Analysis and Design, 1st ed.; John Wiley \& Sons: New York, NY, USA, 1980.

42. Ministry of housing and Urban-Rural Development of the People's Republic of China. Durability Evaluation Criteria for Concrete Structures; China Architecture \& Building Press: Beijing, China, 2007. 